\title{
Editorial
}

Folia Phoniatrica
et Logopaedica

\section{The New Audiology Committee of the IALP Cooperates with the WHO in the Global Work on Problems of Hearing-Impaired People}

\author{
Katrin Neumann \\ Clinic of Phoniatrics and Pediatric Audiology, University of Frankfurt/Main, Germany
}

A new Audiology Committee of the International Association of Logopedics and Phoniatrics (IALP) has recently been founded. An Audiology Committee had already existed before, but a new one was initiated because the World Health Organization (WHO), with which the IALP has informal status, had asked the IALP for more activities in the field of audiology. Therefore, the IALP board decided to refound this committee and asked the author of this editorial to become its chairperson. The IALP president sent a message to the WHO with a statement that the IALP Audiology Committee will collaborate with the WHO to develop guidelines for the screening of neonates, children, and adults for deafness and hearing loss. After a period of searching for members since fall 2006, the committee was officially established in August 2007 during the 27th IALP World Congress in Copenhagen, Denmark.

The committee consists of members who represent all continents and all specializations in the field of audiology, and who are enthusiastic and willing to work voluntarily on a global network to improve the health and quality of life of persons with hearing disorders. Members come from Germany, China, Canada, the USA, Australia, Serbia, Egypt, Chile, Brazil, Sweden, and India.

The Audiology Committee has developed a working plan for the next 3 years which includes a variety of initiatives, activities, and projects as described in the following sections.

\begin{tabular}{ll}
\hline KARGER & ( 2007 S. Karger AG, Basel \\
Fax $+41613061234-7762 / 08 / 0601-0001 \$ 24.50 / 0$ \\
$\begin{array}{l}\text { E-Mail karger@karger.ch } \\
\text { www.karger.com }\end{array}$ & $\begin{array}{l}\text { Accessible online at: } \\
\text { www.karger.com/fpl }\end{array}$
\end{tabular}

Because a special motivation of audiologists to work in the IALP and to visit its congresses was lacking so far, the Audiology Committee should improve this situation by initiatives which increase the attractiveness of audiology in the IALP. Effective actions and projects, symposia, publication of guidelines, a special edition of Folia Phoniatrica et Logopedica on audiology as well as articles on audiological topics in this journal, and an attractive webpage are seen as efficient ways to reach this goal and are planned. With these activities, the Audiology Committee aims to increase international visibility of itself and of audiology within the IALP.

Currently, the committee projects are aligned with the aims of the WHO in the field of audiology. One of the WHO projects is to launch the provision of appropriate and affordable hearing aids and services worldwide, especially in developing countries. Another WHO initiative is the encouragement of countries, with WHO technical support, to conduct random sample, populationbased prevalence and cause surveys of deafness and hearing impairment. The data will be used in planning, determination of priorities, economic analysis, and raising awareness. A global data bank on deafness and hearing impairment is being developed using data from the WHO Protocol Surveys and other published and unpublished sources. A forthcoming activity will assess cost-effectiveness of interventions against deafness and hearing impairment as part of an initiative on the Economic

Prof Dr. Katrin Neumann, Klinik für Phoniatrie und Paedaudiologie Johann-Wolfgang-Goethe-Universität, Theodor-Stern-Kai 7, Haus 7A DE-60590 Frankfurt/Main (Germany)

Tel. +496963015775, Fax +496963015002

E-Mail Katrin.Neumann@em.uni-frankfurt.de 
Analysis of Sensory Disabilities. The new IALP Audiology Committee has already started to work in close cooperation with the WHO on the described aims.

The WHO has published useful audiological information, guidelines, reports, and manuals which are available on its website (http://www.who.int/topics/deafness/en/), such as the WHO Training Resource for Primary Ear and Hearing Care - a set of four training manuals (basic level, intermediate level trainer's manual, intermediate level student's workbook, advanced level) aimed at managing ear diseases and reducing hearing problems in developing countries. Other WHO publications are the Guidelines for Hearing Aids and Services for Developing Countries, a Fact Sheet on Deafness and Hearing Impairment, reports on WHO workshops on special topics of audiology such as Hearing Aids and Services - Needs and Technology Assessment for Developing Countries or Prevention of Hearing Impairment from Chronic Otitis Media, reports on informal consultations, such as on prevention of noise-induced or ototoxic hearing loss, and a preliminary review of the available survey data. It is recommended to distribute these publications to professionals in the field of audiology and communication disorders.

The activities and projects of the IALP Audiology Committee should be in accordance with a new global initiative, WWHearing - World Wide Hearing Care for Developing Countries, which was founded in 2003 (http:// www.wwhearing.com/). The mission of this initiative is to promote better hearing through the provision of affordable and suitable quality hearing aids and services with priority in developing countries and underserved communities, within the framework of the WHO Guidelines for Hearing Aids and Services for Developing Countries.

The committee chair will join the WHO/WWHearing Fifth Workshop on the Provision of Hearing Aids and Services for Developing Countries in Geneva, Switzerland, on November 8-9, 2007, and give a presentation on the aims and planned activities of the Audiology Committee. The cooperation between the IALP Audiology Committee, the WHO, and WWHearing will be specified there. Two committee members have already worked for the $\mathrm{WHO}$ in the field of audiology (Xingkuan $\mathrm{Bu}$, China; Peter Alberti, Canada). Together with the committee chair they met Dr. Andrew Smith, who represents audiology in the WHO, during the National ORL-HNS Congress of China in Nanjing, October 11-15, 2007.

The Audiology Committee aims at an input from and a cooperation with other organizations in the field of audiology, such as the International Society of Audiology
(ISA), Hearing International (HI), and the European Federation of Audiology Societies (EFAS). Several committee members are board members or presidents/vice presidents of these societies and will stimulate them to become affiliated societies of the IALP, which is currently cooperating with 55 affiliated societies in the field of communication disorders from 35 countries.

Committee meetings take place during the triennial IALP world congresses. Audiologists from all over the world are invited to attend these congresses which include special sessions on audiological topics. An additional committee meeting in the interval between these conferences is planned, which will be combined with a symposium on central auditory processing disorders. The symposium aims at the following issues: (1) to attract students and professionals in the field of audiology and possible new IALP members, preferably in a threshold country, where special regional or national programs about the improvement of health services for people with hearing disorders could be supported by an audiological symposium; (2) to effectively promote knowledge about a special topic of interest in contemporary audiology; (3) to provide proceedings as a fundament for a special edition of Folia Phoniatrica et Logopedica, and (4) to support the financing of committee meetings, especially for members from developing and threshold countries.

Professionals in the field of audiology are encouraged herewith to submit articles to Folia Phoniatrica et Logopedica, which has recently increased its impact factor to 0.66 . The committee members will also submit manuscripts devoted to audiologic subjects to this journal and will stimulate other audiologists to do so. A special edition of Folia Phoniatrica et Logopaedica on central auditory processing disorders is planned for the future.

A new webpage of the Audiology Committee on the website of the IALP informs about the committee and its planned projects, activities, and publications. It contains links to the WHO and WWHearing.

The following main projects of the committee are planned for the next 3 years:

(1) In cooperation with Special Olympics, the worldwide largest program of training and competitions of people with intellectual disabilities, guidelines on regular examinations of the audiological/otological status and continued treatment of ear and hearing disorders of persons with intellectual disabilities will be elaborated. This idea originated because hearing screenings during Special Olympic games in the last years showed that at least one quarter of persons with intellectual disabilities have peripheral hearing disorders, and many of them also cen- 
tral auditory processing disorders. Hearing impairments can be treated well if detected early and controlled regularly. Thus, national programs have to be established for regular audiological/otological care for this underserved population. Two committee members work in the Healthy Hearing program of Special Olympics. The guidelines translated into several languages - will also be published on the committee webpage.

(2) The Audiology Committee will support the implementation of early detection and intervention programs of infant hearing loss, especially in developing or threshold countries. Because such programs should guarantee a high quality from the beginning, the committee will in cooperation with the WHO and WWHearing - support the implementation of quality assurance tools and procedures with respect to tracking, follow-up, database matters, training of the screening staff by guidelines, and software provision for an international Newborn Hearing Screening database. A cooperation among committee members with China has already started during which committee members developed a software for a Newborn Hearing Screening database and adjusted it for an application in China. This software enables transfer of data from a screening device directly to a central server as well as storing and processing in a database, and provides the basis for an efficient tracking system.

(3) Guidelines on education for professionals in audiology will be elaborated in cooperation with the WHO and WWHearing. They should aim at the prevention of hearing loss by noise, infections, ototoxic drugs, and parental consanguinity. Other guidelines will focus on the improvement of the 'world of hearing' by suggesting facilitations of environmental conditions related to hearing for normal-hearing persons and for persons who are hard of hearing. The guidelines will be available on the webpage and will be distributed among professionals and affiliated societies.

(4) In cooperation with the WHO and WWHearing, the Audiology Committee will work on an international network for access to and service of affordable hearing aids and cochlear implants in developing countries as described above. One program on the delivery of low-cost but appropriate hearing aids with solar-driven rechargeable batteries runs in India and is supported by the Indian member of the Audiology Committee. Furthermore, the committee has already started discussions and meetings with hearing aid and cochlear implant companies on this topic. A study to provide people with intellectual disabilities during Special Olympics sports events with affordable hearing aids has been initiated by two committee members and started in 2006.

The members of the new Audiology Committee hope to spark interest among professionals in the field of audiology with their activities and to contribute significantly with their projects to the improvement of the situation of hearing-impaired people in the world. 